\title{
Scalable and Accessible Crash Hot Spot Detection for Traffic Law Enforcement
}

\author{
Beau Burdett*, Ran Yi, Steven T. Parker, Andrea Bill, David A. Noyce \\ Department of Civil and Environmental Engineering, University of Wisconsin-Madison, Madison, WI, USA \\ Email: ^bburdett@wisc.edu, ryi22@wisc.edu, sparker@engr.wisc.edu, bill@wisc.edu, danoyce@wisc.edu
}

How to cite this paper: Burdett, B., Yi, R., Parker, S.T., Bill, A. and Noyce, D.A. (2021) Scalable and Accessible Crash Hot Spot Detection for Traffic Law Enforcement. Journal of Transportation Technologies, 11, 265283.

https://doi.org/10.4236/jtts.2021.112017

Received: February 22, 2021

Accepted: April 25, 2021

Published: April 28, 2021

Copyright $\odot 2021$ by author(s) and Scientific Research Publishing Inc. This work is licensed under the Creative Commons Attribution International License (CC BY 4.0).

http://creativecommons.org/licenses/by/4.0/

(c) (i) Open Access

\begin{abstract}
Law enforcement agencies have begun utilizing traffic and crash data to improve traffic law enforcement delivery. However, many agencies often do not have the resources or expertise to harness fully the benefits this data offers. A free to use, scalable traffic crash hot spot detection tool was developed to aid law enforcement agency decision makers, statewide to the local municipality level. The tool was developed to identify crash hot spots algorithmically with a range of customizable parameters based on location, date and time, and crash factors, enabling quick, dynamic queries. These capabilities provide the ability for law enforcement agencies to conduct "what if" analyses and make data-driven allocation decisions, placing officer resources where they are most needed. The two-step algorithm first identifies potential hot spots based on crash density and then ranks each hot spot using a standardized z-score measure of relative significance. To test the viability of the tool, a pilot was conducted identifying 27 hot spots across Wisconsin where targeted enforcement was then deployed. Despite officer skepticism, results from the pilot found officers at sites targeted for speeding and seatbelt violations were nearly twice as likely to initiate traffic stops compared to non-targeted hot spots. Empirical Bayes before-and-after crash analyses found fatal and injury crashes reduced significantly by nearly $11 \%$ during the months with targeted enforcement, while property damage crashes and total crashes were unchanged. Overall, the results show the algorithm can identify hotspots where, coupled with targeted enforcement, traffic safety improvements can be made.
\end{abstract}

\section{Keywords}

Hot Spots, Law Enforcement, Traffic Data, Crash Data

\section{Introduction}

In recent years, more timely, complete, and accurate crash and traffic data have 
become available, allowing law enforcement agencies to further the traffic safety mission in ways not possible before. Harnessing this data can lead to data-driven law enforcement allocation decisions, putting officers when and where they are most needed. However, these raw data sets are large, require processing, and can require a level of expertise or funding prohibitive to some agencies. In response, a free to use, open source, scalable predictive crash hot spot detection tool was developed to aid law enforcement decision makers at all levels.

Often, data analyses can be expensive, time consuming, and require a high level of expertise. Nowadays, sophisticated analytics programs exist at many large agencies, but the technology can be too cost prohibitive at smaller agencies [1]. At a time when law enforcement agencies are asked to do "more with less", and personnel can view traffic enforcement as a less important aspect of law enforcement [2], agencies may be unwilling or unable to make costly investments into technology and proactive traffic enforcement approaches. In 2017, the Community Maps crash mapping and hot spot detection tool was developed by the University of Wisconsin-Madison Traffic Operations and Safety (TOPS) Laboratory in partnership with the Wisconsin State Patrol (WSP) to bring these technologies and analysis capabilities to all law enforcement agencies in Wisconsin without the need for costly investment [3].

The primary goal of the tool was to analyze crash data to algorithmically determine hot spots. Several requirements and constraints were needed to make the tool useful for law enforcement agencies. The tool utilized crash mapping on all roadway classifications, including local roads. Hot spots could be investigated and analyzed based on crash factors aligned to Wisconsin's Strategic Highway Safety Plan (SHSP) prioritized issue areas with an enforcement aspect, such as impaired driving, teen driving, speeding, and commercial motor vehicles, with an eye toward scheduling, allowing for time of day/day of week analyses. Discrete sets of well-defined locations for targeted enforcement are output in lieu of a generalized heatmap of crash density. The tool was developed to be used by all levels of law enforcement agencies (State, County, and local police departments), either individually or through interagency partnerships. The tool creates a predictive decision support tool placed directly into the hands of agencies allowing quick, dynamic queries and "what-if" analyses.

As part of the rollout, researchers were interested in studying how the needs of law enforcement agencies translate into specifications for a hot spot detection tool and resource allocation decision support tool. Further, this paper provides a case study for the use and usefulness of the hot spot detection tool in a targeted enforcement pilot. The pilot provided an opportunity to evaluate targeted law enforcement efforts made possible with the new hot spot detection tool. While this tool was developed for the WSP specifically, these tools can have a broad impact on all law enforcement agencies. This data-driven hotspot detection algorithm can help agencies grapple with ever increasing responsibilities and large, complicated datasets to more effectively allocate their resources. 


\section{Literature Review}

\section{Proactive Policing, and Place-Based Policing Approaches}

Historically, policing has been largely reactive in nature (e.g., a crime occurs and law enforcement responds). Proactive policing is an innovative policing approach with its roots in the 1970's. The goal of proactive policing is crime prevention, aimed at "targeting broader underlying forces at work" [4]. Place-based approaches are a family of proactive policing strategies capitalizing on research results showing how crime concentrates at microgeographic levels [5] [6] [7]. Two common strategies that fall within place-based policing approaches are hot spots policing and predictive policing. While these approaches have large placebased components, often policing requires a hybrid approach, combining placebased approaches with community-based approaches or problem-oriented policing.

Hot spots policing, allocating law enforcement resources to an area of high crime, is a widespread practice in the United States. In a 2013 National Police Research Platform (NPRP) survey, $91 \%$ of responding agencies had some form of hot spots policing policy [8]. The first hot spots policing strategy was developed in the 1995 Minneapolis Hot Spots Patrol Experiment [6]. Since then, research has shown hot spots policing to be effective at reducing crime [4] [9]. Further, allocating police resources to hot spots does not lead to crime displacement, and even has a positive effect on crime in adjacent areas [10] [11] [12]. However, the extent to which these results are applicable to traffic safety enforcement is less understood.

Predictive policing approaches make use of "predictive algorithms based on combining different types of data to anticipate where and when crime might occur and to identify patterns among past criminal incidents" [4]. In the context of place-based policing approaches, research results are inconclusive whether predictive policing has an advantage over traditional methods of hot spots policing [13] [14]. Despite the inconclusive results, a 2014 Police Executive Research Forum (PERF) survey found 38\% of agencies used predictive policing [15]. The success of predictive policing techniques has led agencies to consider their application for targeted traffic safety enforcement.

\section{Crash and Crime Hot Spots Identification}

Crime mapping has a long history, beginning in the 1800s [16]. Crash mapping dates back to the early 20th century when Vollmer, the Berkeley Chief of Police, started pinning traffic crashes and calls for service to a map [17]. Modern crime and crash mapping has become a much more sophisticated endeavor with increasingly advanced and accessible computing capabilities. Common methodologies include clustering techniques, spatial analyses, and machine learning techniques. Risk Terrain Modeling is a modeling technique incorporating environmental surroundings with crime occurrence to calculate risk of crime in a geographic area. The report Mapping Crime: Understanding Hot Spots provides a comprehensive list of crime mapping techniques employed by law enforcement agencies [18]. 
Crash prediction methodologies are described in the Highway Safety Manual (HSM). Within the HSM the process for determining hazardous locations, or "sites", is referred to as network screening [19]. The purpose of network screening is to determine sites with potential for crash or severity reduction. Network screening utilizes crash, roadway facility information, and other traffic data to determine crash hot spots at segments and/or intersections. These crash hot spots are based on crash frequencies, crash rates, or some combination [20]. The HSM includes 13 distinct methods for ranking sites. Some methodologies define hot spots as sites above a calculated threshold to further differentiate between candidate sites. More sophisticated methodologies account for regression-tothe-mean bias through the use of Safety Performance Functions (SPFs), and the use of Empirical Bayes (EB). See Hauer [20] and Lord and Mannering [21] for a more complete canvas of Network Screening methodologies.

Spatial analysis methodologies used in transportation safety analyses include spatial autocorrelation, geographically weighted regression (GWR), density-based spatial clustering methods [22] [23] [24], kernel density estimation (KDE), Gi*, and machine learning techniques. Spatial analyses have been used to study weather, cross median crashes, and injury severity [25] [26] [27] [28]. For the state of the art of spatial traffic safety analyses see Ziakopolous and Yannis [29]. KDE and $\mathrm{Gi}^{*}$ are most similar to the proposed algorithm and are discussed further.

The Getis-Ord $\mathrm{Gi}^{*}$ statistic is a local statistic within the $\mathrm{G}$ family of statistics [30] [31]. Gi* is used to identify spatial clustering patterns such as hot spots within a given area. The Getis-Ord $\mathrm{Gi}^{*}$ statistic has been applied to detect statistically significant traffic crash hotspots [32] [33] [34]. KDE is a non-parametric method to estimate the probability density function of a random variable. KDE sums individual events contribution in space, the surface is smoothed creating an estimate of density. KDE has been widely used for various purposes, such as point or line data smoothing, risk mapping, and hotspot detection. KDE is a popular method of traffic crash hotspots analysis, producing a density estimate at every point in 2-D space. However, often the analysis is restricted to the roadway network [35].

\section{Data Driven Approaches to Crime and Traffic Safety (DDACTS)}

One of the first models to extend proactive policing concepts from crime to traffic safety was the Data-Driven Approaches to Crime and Traffic Safety (DDACTS) model. DDACTS, developed in partnership between the National Highway Transportation Agency (NHTSA) and the Department of Justice, draws on "the deterrent value of highly visible traffic enforcement ... to reduce the incidence of crime, crashes, and traffic violations in communities" [36]. DDACTS was developed to "integrate location-based crash, crime, calls for service and enforcement data to establish effective and efficient methods for deploying law enforcement resources" [36]. A cornerstone of DDACTS is data analysis with a focus on utilizing mapping software to identify areas of overlapping crime and traffic crashes. The primary stated objective of DDATCS is to "reduce the incidence of crashes and crime" through deterrence, such as High Visibility En- 
forcement (HVE) [36]. Combining highly visible and proactive law enforcement strategies, HVE is a proven traffic safety approach designed to deter risky driving behaviors and subsequently reduce crashes [37]. However, expenditures of HVE increase rapidly compared with traditional law enforcement practices [38].

In 1994, a DDACTS case study found increased traffic enforcement resulted in significant reductions in crashes, crime, and calls for service [39]. Since then several studies have shown the efficacy of patrolling overlapping areas of high crime and crashes [37] [40] [41] [42]. Further, employing DDACTS reduced police dispatch times by up to $17 \%$ when patrolling crash and crime hot spots [43].

\section{The Wisconsin Community Maps System}

The University of Wisconsin-Madison TOPS Laboratory developed the Community Maps predictive crash hot spot detection tool in partnership with the Wisconsin Department of Transportation (WisDOT) Bureau of Transportation Safety (BOTS) to support and enhance efforts by the WSP and local law enforcement agencies to "utilize safety data to target law enforcement activities" [44]. The hot spot detection tool provides a high-level decision support system to help law enforcement agencies optimize staffing allocations and enhance visibility in the right locations at the right times. Community Maps is an all-road crash mapping platform with a predictive crash hot spot detection tool that allows for fast, dynamic queries. The resulting visualization from a query can be presented as a heatmap representing density or pin map. Significant hot spots, or "Analysis Areas" are further highlighted as potential areas for targeted enforcement activities based on a likelihood of future crashes with similar attributes, as shown in Figure 1. Analysis areas are shown as bold rectangles that display over the heatmap, providing geographic visualization of significant hot spots.

The hot spot detection tool includes all federal, state, and local roads in Wisconsin, building on past crash mapping work [45]. The inclusion of local roads allows for results that are scalable from statewide or regional analyses to local municipality hot spot queries. Combining highway and local road crashes into the analysis is also an essential consideration for law enforcement activities that are geared towards driver behaviors and patterns that are not typically restricted to specific stretches of highway. However, inclusion of local roads disallows the possible inclusion of exposure such as traffic volumes to the algorithm.

The Community Maps hot spot detection tool is designed to scale to all levels of law enforcement agencies, from State Patrol to County Sheriff to municipal law enforcement agencies. The scalable nature of the algorithm correspondingly provides the ability to filter based on a range of locations allowing for any agency to select the appropriate jurisdiction for further analyses or to support interagency partnerships. This scalability provides utility for agencies of all sizes in Wisconsin and provides opportunity for data-driven policing previously unattainable.

The Community Maps hot spot detection tool is real-time, reliable and multi-purpose, allowing users to dynamically conduct targeted queries based on 


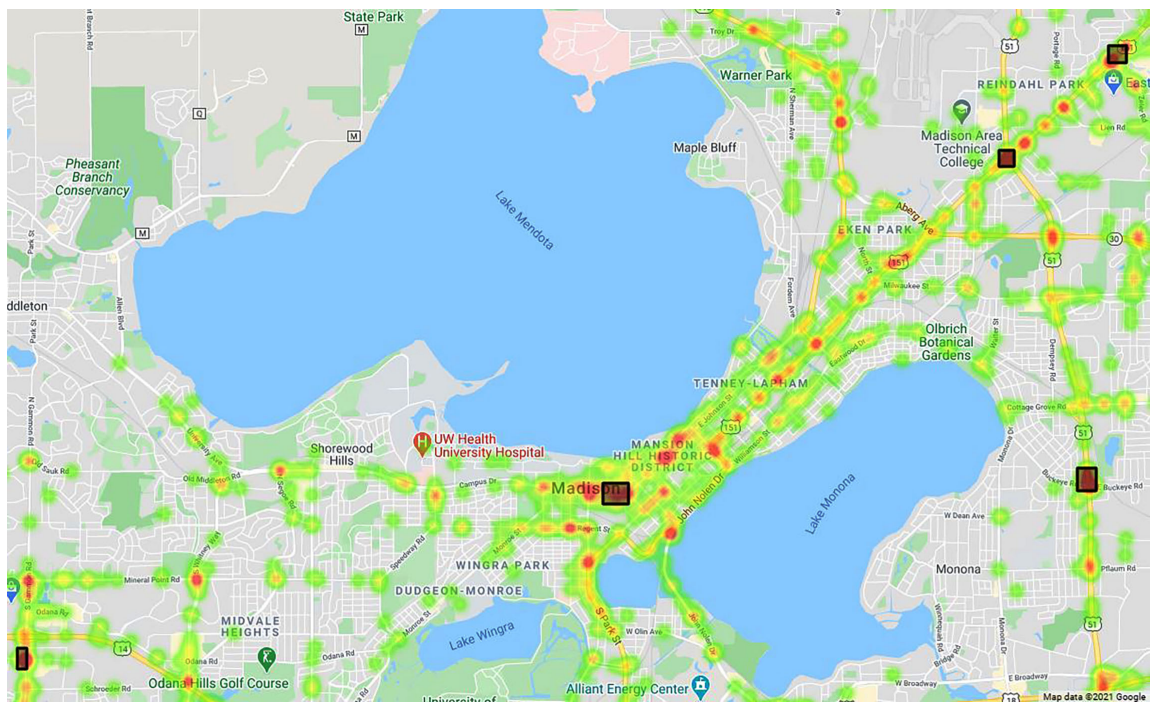

Figure 1. Community Maps heatmap and hot spot analysis example.

high-level parameters, with results available in multiple formats. The tool allows analyses based on historical trends and crash factors, with the dynamic nature enabling agencies to explore different outcomes based on Wisconsin's Strategic Highway Safety Plan (SHSP) issue areas (such as impaired and distracted driving) and resource-driven constraints (e.g., weekend shifts for the next ninety days). The hot spot detection tool creates a decision support tool placed directly into the hands of law enforcement agencies, allowing quick dynamic queries and "what-if" analyses. To achieve these goals, the tool includes a user interface designed to tailor queries based on geography, dates and times, and crash factors.

Crash flags can be used to investigate safety concerns based on driver behavior or other crash factors. The list of potential crash flags for users was chosen to match Wisconsin SHSP emphasis areas. Flags included alcohol, drugs, bicycle and pedestrian flags, motorcycle and commercial motor vehicle (CMV) flags, age related flags to filter for teen drivers or drivers over 65, work zone crashes, and issues such as speeding, distracted driving, and seat belt compliance. Further the tool provides users the ability to filter based on injury severity. While it is often typical for law enforcement to focus on injury crashes, an important consideration when developing the tool was to look at the behaviors behind crashes and not just the most severe injuries and fatal crashes. The tool can help provide data-driven insights that would have been impossible to discern previously. The ability to apply location, date and time, and crash filters allows for customized queries for more targeted safety enforcement scenarios. For example, locations with a high concentration of teen-driver crashes on nights and/or weekends within a particular region could be identified. These filters and flags allow an agency to highly customize their queries to aid scheduling with data-driven officer allocation decisions. However, making queries too restrictive through too many flags or a date range that is too small can result in a small crash sample that will not support a statistically significant result. The data-driven hot spot detection tool allows for enforcement allocations that can targeted more effectively. 
The ability to modify and restrict the date range, month of year, day of week, and time of day of data is tied to timeliness. Timeliness of crash data availability has been improved due to full electronic crash reporting and report form modernization efforts [46]; queries can contain crashes that occurred the previous day. The tool can provide law enforcement agencies an easy-to-use, data-driven approach to ensure the scheduling of patrols can have the most impact with given constraints on law enforcement officer hours.

The filtered set of crashes serve as input to the hot spot detection algorithm, which generates a set of confidence ranked hot spots, or "Analysis Areas", representing a prioritized list for targeted traffic enforcement. The Analysis Areas are represented as rectangular regions on the map (shown in Figure 2). The tool shows the relative concentration of crash types (alcohol, teen driver, etc.) to target hot spots aligned to SHSP prioritized issue areas. Although the tool is intended to provide a high-level and automated identification of crash hot spots, individual crashes with linked police crash reports can be displayed for fine grain analysis and verification. Moreover, the tool allows for manual resizing of Analysis Areas, as the tool is meant to support rather than replace human judgment.

\section{Two-step Algorithm}

A description of the algorithm for generating the Analysis Areas follows. Define

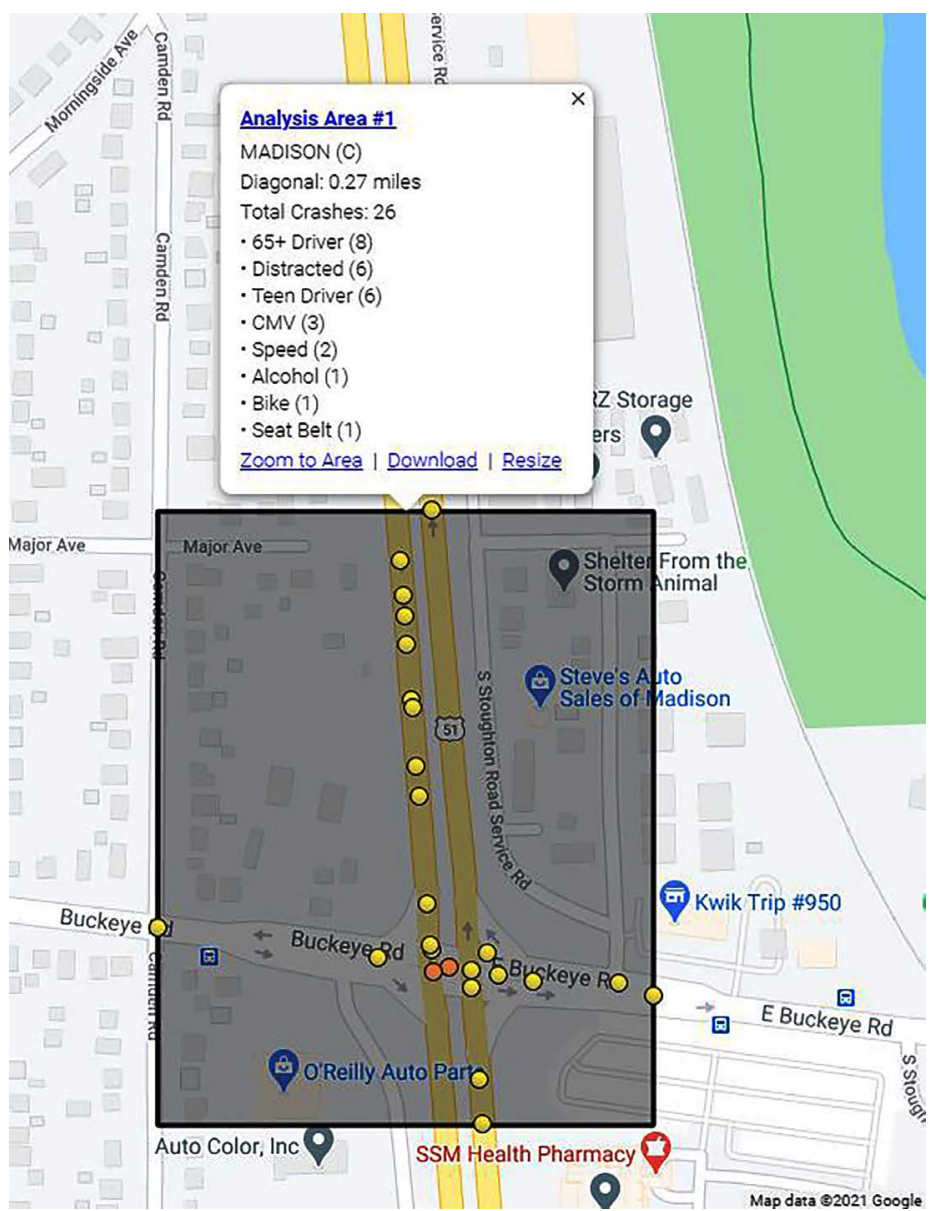

Figure 2. An example of one hotspot analysis area. 
$P$ as the total number of desired Analysis Areas, $T$ is the minimum number of crashes per Analysis Area, $L$ is the minimum analysis radius for computing the crash density measures, and $U$ is the maximum analysis radius for computing the crash density measures. The values for $P, T, L$, and $U$ are configurable by the user. When $L=U$, the analysis areas have a fixed size. Setting $L<U$ allows the algorithm to consider a range of analysis area sizes in order to adapt to different scenarios, e.g., urban areas typically lead to tighter analysis areas, whereas rural locations may require larger areas. The algorithm defaults to a minimum search radius of 0.1 miles, which corresponds roughly to a city block, and a maximum search radius of 5 miles to accommodate rural settings.

A "crash neighborhood" $N_{i}(j)$ is defined as the circular area around a center crash $i$ that contains its $j$ closest crashes, as shown in Figure 3. The radius of $N_{i}(j)$ is therefore the distance between crash $i$ and crash $j$. Each crash $i$ generates a sequence of neighborhoods $N_{i}(j)$ for $j=1, \cdots, n$, where $n$ is the number of crashes in the sample set. The "crash density" $D_{i}(j)$ for neighborhood $N_{i}(j)$ provides the basic measure for analysis:

$$
D_{i}(j)=\frac{\operatorname{card}_{i}(j)}{\pi * \operatorname{radius}(i, j)^{2}}
$$

where

radius $_{i}(j)$ is the radius of $N_{i}(j)$, and

$\operatorname{card}_{i}(j)$ is the cardinality of $N_{i}(j)$.

The cardinality function may take weighted or unweighted forms. In its unweighted form, $\operatorname{card}_{i}(j)=j+1$, the simple count of crashes in the neighborhood. When

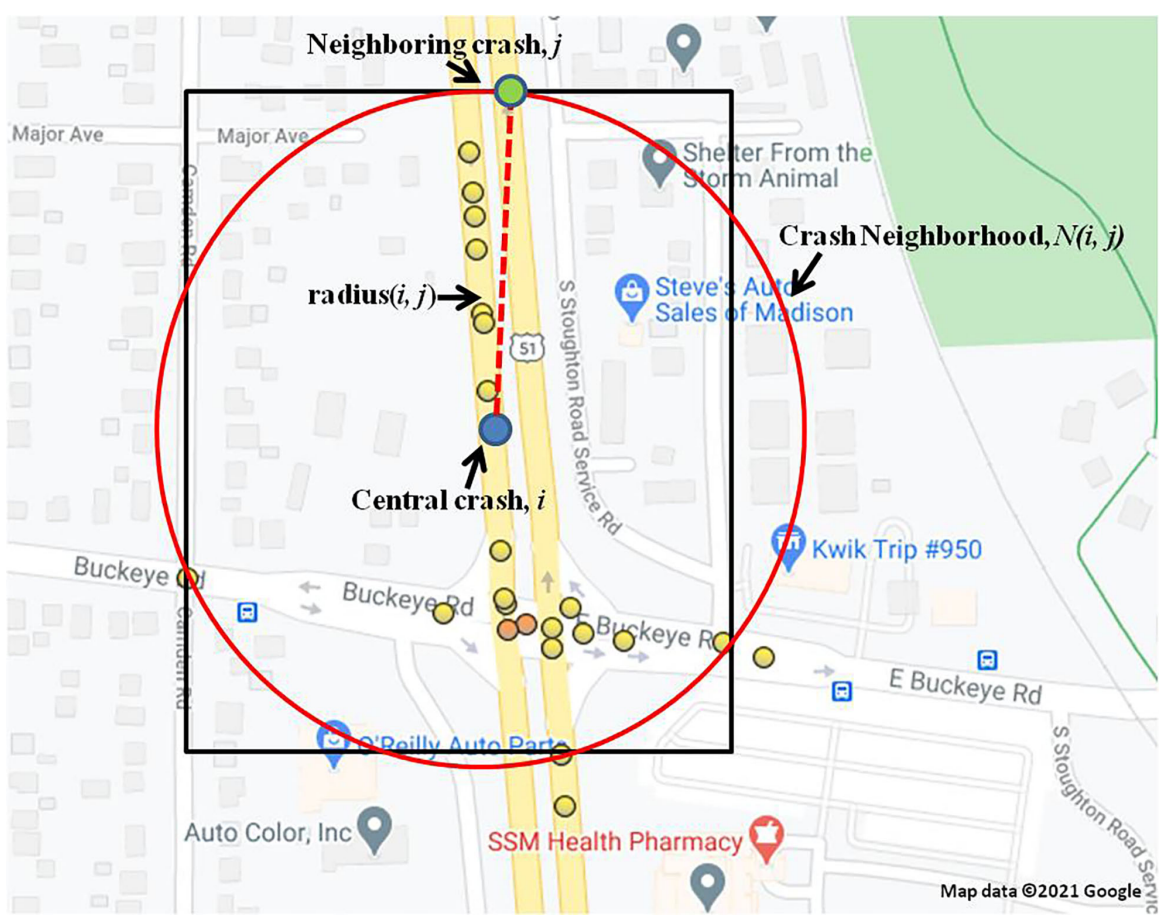

Figure 3. Crash neighborhood of crash $i$. 
one or more crash flags are selected, the $\operatorname{card}_{i}(j)=\sqrt{\operatorname{count}\left(\operatorname{flag}_{1}\right)^{2}+\cdots+\operatorname{count}\left(\operatorname{flag}_{k}\right)^{2}}$. For each crash $i$, the maximum $D_{i}(j)$ for all $j$ is given as $D^{*}(i)$. The algorithm proceeds iteratively, identifying the crash neighborhood with the next highest crash density until the top $P$ neighborhoods are obtained, or there are no more solutions. The other details are intended to ensure the resulting Analysis Areas are distinct (do not overlap) and that they satisfy the user-defined thresholds.

To identify crash hotspots for targeted traffic safety enforcement, a two-step hot spot detection algorithm is proposed. First, the sample set of crashes returned from the database query is analyzed to obtain best-fit "Analysis Areas" representing well-defined zones for targeted enforcement. The Analysis Areas are ranked according to their crash density measures, described below. The second step is to generate a standardized $z$-score for each Analysis Area to quantify the relative significance of each area as a hotspot. The $z$-score also provides for the ability to exclude Analysis Areas that do not meet a desired threshold.

\section{Step 1: Hotspot Detection}

Initialization: Without loss of generality, the algorithm starts from a set of crashes returned from a crash data query.

set $p=0$

for $i=1$ to $n$

let $N^{*}(i)$ be the crash neighborhood with the highest crash density in $N(i)$

for $L \leq \operatorname{radius}_{i}(j) \leq U$ and $\operatorname{card}_{i}(j) \geq T$ :

find $N(i)=\left\{N_{j}(k)\right\}$ for all $j, k$ excluding crashes in $\left\{N^{*}(1), \cdots, N^{*}(i-1)\right\}$

if $N^{*}(i)==\{\varnothing\}$ : break

else:

if $N^{*}(i)$ intersects with $\left\{N^{*}(1), \cdots, N^{*}(i-1)\right\}$ : continue

else:

$p=p+1$

set $A(p)$ as the minimum bounding rectangle around $N^{*}(i)$

if $p==P$ :

break

else:

continue

end

where the calculation of Step 1 is based on the circular area $N^{*}(i)$ with the highest crash density. Once the $N^{*}(i)$ is found without intersecting with previous calculated Analysis Areas, we display the circular area $N^{*}(i)$ in terms of $A(p)$ which is the minimum bounding rectangular area of $N^{*}(i)$, since that is 
typically a tighter fit (though not always) and works better for visualization on the crash map. Moreover, the loop obtains each $N^{*}(i)$, one at a time, eliminating crashes from previous neighborhoods and making sure that each new neighborhood is distinct.

Step 2: Z-Score Analysis

for $p=1$ to $P$

calculate the $z$ value for $A(p)$

if $z>0$ :

continue

else:

delete $A(p)$

end

where $z=\frac{x-u}{S}$, where $x$ is the density of $N^{*}(i)$ corresponding to $A(p), u$ is the average $D^{*}(i)$ for all $i$ and $S$ is the standard deviation of $D^{*}(i)$ for all $i$. The $\mathrm{z}$-score is taken over all $D^{*}(i)$ for $i=1, \cdots, n$, that satisfies the given thresholds. Furthermore, the highest-ranked neighborhood also has the highest ranked $\mathrm{z}$-score, which means ranking by density is equivalent to ranking by $\mathrm{z}$-score. Since $\mathrm{z}$-score analysis is applied in all cases, when the sample size is too small or the dataset is not normally distributed, the z-score analysis will be less reliable as a measure of significance.

\section{Targeted Hot Spot Enforcement Pilot}

As part of the Community Maps predictive crash hot spot detection tool roll out, a targeted traffic enforcement pilot was conducted. The tool was used not only to detect promising sites for targeted enforcement, but also to develop educational outreach material for the pilot, utilizing a multi-pronged approach to improve traffic safety. The tool was used to determine hot spots across three jurisdictions of the WSP: the Southwest, Northeast, and Northwest regions. The WSP conducted the targeted enforcement in conjunction with county sheriff offices and local police departments. Within these three regions, 27 hot spots in six counties were identified by the hot spot detection tool. Beginning in the summer of 2019, targeted enforcement at these locations began. Enforcement of each hot spot was conducted during summer months (June through August), fall months (September through November), or both. A complete list of hotspots and corresponding driver behavior issues are listed in Table 1.

Of the 27 hotspot locations, 11 (40.7\%) had targeted enforcement in both summer and fall months, eight (29.6\%) sites during summer months, and eight (29.6\%) sites during fall months only. Specific driver behavior issues leading to safety concerns were noted at 23 of the hotspots. These factors included distracted driving, speeding, seatbelt violations, and alcohol-related crashes.

After determination of targeted enforcement sites, outreach was conducted. The pilot was promoted through local media: interviews and ride-alongs with 
Table 1. Hotspot high visibility enforcement pilot locations.

\begin{tabular}{|c|c|c|c|c|}
\hline Site & County & Location & Enforcement Period & Listed Behavior Issues \\
\hline 1 & Brown & Main St \& University Ave & Summer, Fall & Seatbelt, Motorcycle \\
\hline 2 & Brown & Dousman/Walnut St \& N Broadway & Summer & Distracted \\
\hline 3 & Brown & W Mason St & Summer, Fall & Teen \\
\hline 4 & Brown & STH 172 (Ashwaubenon) & Summer, Fall & Distracted \\
\hline 5 & Brown & Main Ave (STH 32) & Fall & Teen \\
\hline 6 & Chippewa & STH 124/USH53 \& USH 29 & Summer, Fall & Distracted, Speeding \\
\hline 7 & Chippewa & Grove/Superior St \& River/Elm St & Summer & N/A \\
\hline 8 & Chippewa & Main/Vine St \& 17th Ave & Summer & Distracted, Seatbelt \\
\hline 9 & Chippewa & E Canal St \& Bridge St/Park Ave & Fall & Distracted, Alcohol \\
\hline 10 & Chippewa & US 53 \& Hogarth St/E Melby St & Fall & N/A \\
\hline 11 & Fond Du Lac & S Macy St/S Park Ave \& 4 th St & Summer, Fall & Bike \\
\hline 12 & Fond Du Lac & N Main St \& E Johnson St & Summer & Distracted \\
\hline 13 & Fond Du Lac & STH 45 & Summer, Fall & Teen, Distracted \\
\hline 14 & Fond Du Lac & E Johnson St (STH 23) & Fall & Distracted \\
\hline 15 & Outagamie & STH 441 \& College Ave & Summer & Distracted, Teen, Seatbelt \\
\hline 16 & Outagamie & Northland Ave (STH 15) \& US 41 & Fall & Teen, Speeding \\
\hline 17 & Sauk & STH 12 (Lake Delton) & Summer & Bike, Teen, Distracted \\
\hline 18 & Sauk & STH 12 \& I94 & Summer, Fall & Speeding \\
\hline 19 & Sauk & Main St (Reedsburg) & Summer & N/A \\
\hline 20 & Sauk & W Pike St \& Linn St & Summer & Distracted \\
\hline 21 & Sauk & STH23 \& I94 & Fall & N/A \\
\hline 22 & Sauk & 8th/Water St. \& STH 33/113 & Fall & Distracted \\
\hline 23 & Sauk & Phillips Blvd. (US 12) & Fall & Distracted \\
\hline 24 & Winnebago & STH 47 \& USH 10 Interchange & Summer, Fall & Teen, Distracted, Alcohol, Speeding \\
\hline 25 & Winnebago & Winneconne Ave from I41 to Wisconsin Ave & Summer, Fall & Teen, Seatbelt \\
\hline 26 & Winnebago & Main St (Downtown) & Summer, Fall & Distracted, Alcohol, Seatbelt \\
\hline 27 & Winnebago & I41 from 9th Ave to STH 44 Interchange & Summer, Fall & Teen, Distracted \\
\hline
\end{tabular}

television news programs, radio spots, and social media postings. The hot spot detection tool was used to create county-specific infographics for each pilot site. The pamphlets were distributed throughout the community at local establishments such as gas stations, restaurants, and police stations prior to enforcement. Pamphlets were also distributed by officers when traffic stops were initiated. An example of the pamphlet describing the purpose of the targeted enforcement effort is shown in Figure 4. The front of the pamphlet included information about where the crash hotspots were located and common contributing factors of the 
crashes (Figure 4(a)). On the back of the pamphlet, countywide crash facts including injuries, fatalities, total crashes, and driver behaviors were included (Figure 4(b)).

\section{Citation Analysis}

During the pilot 1163 citations and 2385 warnings were issued. The target driver behaviors of the pilot that had equivalent statute violations were examined more closely, including alcohol-related violations, distracted driving, seatbelt violations, and speed-related violations. Alcohol was a target driver behavior at three hotspot locations and accounted for 3\% of all citations written during the pilot. Distracted driving was a target driver behavior at 16 locations. Seatbelt usage was targeted at five hotspots and accounted for the largest proportion of citations issued during the pilot (29\%), and almost all (90\%) of contacts for seatbelt violations resulted in a citation. Speeding was targeted at four hotspots. Large amounts of discretion were shown with speed-related violations with roughly one-third receiving citations, and the rest warnings.

Citations and warnings from hotspots with targeted behavior issued during pilot months were compared to non-pilot months as a surrogate for enforcement

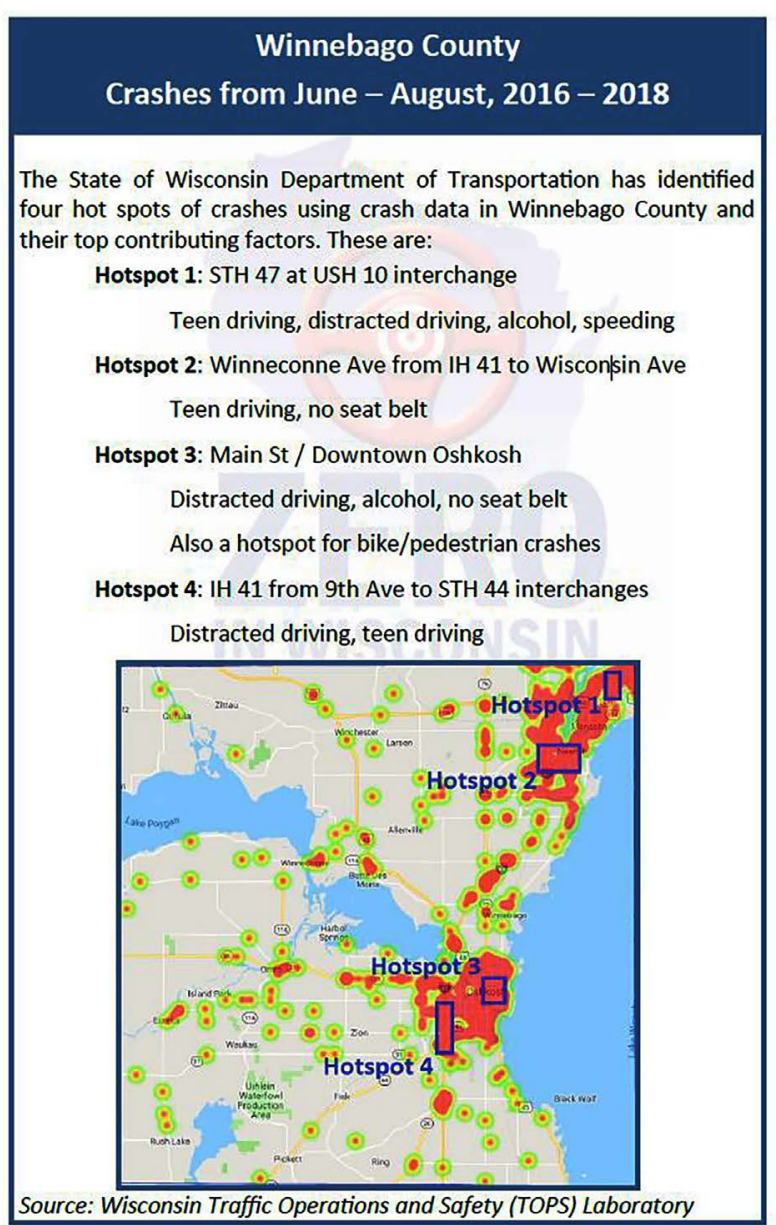

(a)

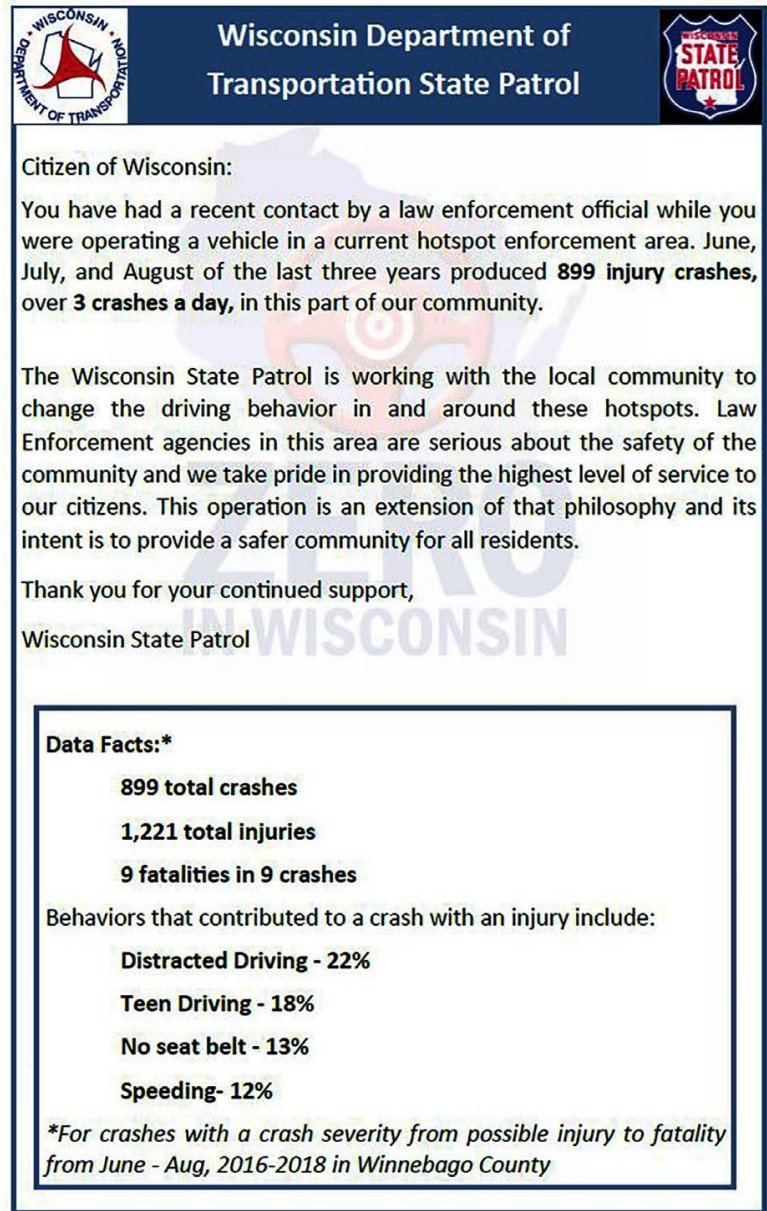

(b)

Figure 4. Hot spot high visibility enforcement pamphlet (a) front and (b) back. 
dosage. Due to small sample sizes, citations and warnings were combined. Only seatbelt violations and speed-related violations had large enough sample sizes to test for significant differences between sites with specific enforcement actions and those without. The frequency of citations and warnings during the pilot months (normalized to citations and warnings per three months) was compared to citations and warnings during months without targeted enforcement. Sites analyzed targeted only the specific enforcement action (seatbelt or speeding). These were compared to sites without any specific targeted enforcement action during the pilot (sites three, five, 10, 11, 19, and 21 in Table 1). This created a 2 $\times 2$ contingency table from which chi-square tests were performed $(\mathrm{df}=1)$ for seatbelt violations (sites one and 25 from Table 1 ) and speeding-violations (sites 16 and 18 in Table 1).

The results of the chi-square test found targeted enforcement had a significant impact on seatbelt violations at $90 \%$ level of confidence $\left(\chi^{2}(1, \mathrm{~N}=63)=3.68, \mathrm{p}\right.$ $=0.055)$, with an odds ratio of 2.19. Targeted enforcement had a significant impact on speed-related violations at $95 \%$ level of confidence $\left(\chi^{2}(1, \mathrm{~N}=171)=\right.$ $4.60, \mathrm{p}=0.032)$, with an odds ratio of 1.88 . Targeted enforcement resulted in nearly twice as many speed-related violations during the pilot compared to non-pilot months as sites where speed was not targeted at $95 \%$ level of confidence, and twice as many seatbelt violations at $90 \%$ level of confidence.

\section{Crash Analysis}

An observational before and after study was implemented to evaluate the effect of the targeted enforcement pilot. Crash data during the months of targeted enforcement (in 2019) were compared to the same months of the three previous years (2016-2018). Empirical Bayes (EB) analysis was performed to quantify the safety effect of the targeted enforcement. As the sites selected were high density crash locations and there were limited observations in the after period, the EB method was chosen to account for site selection bias and regression to the mean [47]. Each hotspot may not be an isolated facility and may include several segments and intersections with unique size geometric and operational features over a specified footprint. Further, the lack of traffic volumes for local roads and short periods of time in the analysis period make use of HSM SPFs difficult. Given these constraints, the method of sample moments was used to calculate the expected number of crashes based on historical observed data from the sites. This method adjusts a site's observed crashes based on crash data variance and reference population average crash counts [19] [47]. The expected number of crashes can be compared to the observed crashes, from which a Safety Effectiveness (SE) measure is derived from the unbiased estimator for the odds ratio.

The safety effectiveness measures the effect of a treatment, in this case the targeted enforcement efforts. When the observed crash frequency decreases compared to the expected number of crashes, the SE is positive. When crash frequency increases, the $\mathrm{SE}$ is negative. The results from the EB analysis can be seen in Table 2. The results include the observed and expected crashes from the 
after period, as well as the safety effectiveness of targeted enforcement at each pilot site.

Across all sites during the targeted enforcement period, there were 290 fatal and injury (FI) crashes, 754 property damage (PDO) crashes, and 1044 total

Table 2. Safety effects of targeted enforcement pilot.

\begin{tabular}{|c|c|c|c|c|c|c|c|c|c|c|c|c|c|}
\hline \multirow[b]{2}{*}{ Site } & \multirow[b]{2}{*}{ Location } & \multicolumn{4}{|c|}{ Fatal \& Injury } & \multicolumn{4}{|c|}{ Property Damage Only } & \multicolumn{4}{|c|}{ Total } \\
\hline & & Obs. & Exp. & SE (\%) & $\mathrm{p}$-value & Obs. & Exp. & SE (\%) & p-value & Obs. & Exp. & SE (\%) & $\mathrm{p}$-value \\
\hline 1 & Main St \& University Ave & 0 & 4 & - & - & 10 & 6 & -58 & 0.320 & 10 & 10 & -3 & 0.931 \\
\hline 2 & Dousman/Walnut St \& N Broadway & 0 & 5 & - & - & 8 & 6 & -27 & 0.598 & 8 & 11 & 27 & 0.598 \\
\hline 3 & W Mason St & 6 & 4 & -36 & 0.560 & 24 & 8 & -215 & $0.015^{* *}$ & 30 & 12 & -157 & $0.011^{* *}$ \\
\hline 4 & STH 172 (Ashwaubenon) & 6 & 4 & -59 & 0.422 & 24 & 8 & -190 & $0.017^{* *}$ & 30 & 12 & -157 & $0.011^{* *}$ \\
\hline 5 & Main Ave (STH 32) & 10 & 9 & -6 & 0.881 & 2 & 4 & 54 & $0.096^{*}$ & 12 & 14 & 12 & 0.669 \\
\hline 6 & STH 124/USH53 \& USH 29 & 9 & 10 & 14 & 0.666 & 3 & 8 & 64 & $0.003^{* *}$ & 12 & 19 & 35 & $0.079^{*}$ \\
\hline 7 & Grove/Superior St \& River/Elm St & 0 & 8 & - & - & 16 & 11 & -47 & 0.281 & 16 & 19 & 15 & 0.513 \\
\hline 8 & Main/Vine St \& 17th Ave & 12 & 13 & 7 & 0.805 & 13 & 7 & -78 & 0.189 & 25 & 20 & -24 & 0.414 \\
\hline 9 & E Canal St \& Bridge St/Park Ave & 4 & 4 & -6 & 0.916 & 18 & 17 & -3 & 0.913 & 22 & 21 & -5 & 0.835 \\
\hline 10 & US 53 \& Hogarth St/E Melby St & 2 & 7 & 71 & $<0.001^{* *}$ & 0 & 16 & - & - & 2 & 22 & 91 & $<0.001^{* *}$ \\
\hline 11 & S Macy St/S Park Ave \& 4 th St & 2 & 7 & 71 & $<0.001^{* *}$ & 0 & 16 & - & - & 2 & 22 & 91 & $<0.001^{* *}$ \\
\hline 12 & N Main St \& E Johnson St & 6 & 6 & -6 & 0.903 & 12 & 17 & 31 & 0.146 & 18 & 23 & 21 & 0.300 \\
\hline 13 & STH 45 & 6 & 6 & -6 & 0.903 & 12 & 17 & 31 & 0.146 & 18 & 23 & 21 & 0.300 \\
\hline 14 & E Johnson St (STH 23) & 6 & 8 & 27 & 0.376 & 15 & 19 & 20 & 0.376 & 21 & 27 & 22 & 0.252 \\
\hline 15 & STH 441 \& College Ave & 2 & 10 & 80 & $<0.001^{* *}$ & 12 & 21 & 44 & $0.011^{* *}$ & 14 & 31 & 55 & $<0.001^{* *}$ \\
\hline 16 & Northland Ave (STH 15) \& US 41 & 16 & 12 & -33 & 0.390 & 4 & 20 & 80 & $<0.001^{* *}$ & 20 & 32 & 38 & $0.013^{* *}$ \\
\hline 17 & STH 12 (Lake Delton) & 10 & 12 & 17 & 0.563 & 25 & 20 & -22 & 0.432 & 35 & 32 & -8 & 0.704 \\
\hline 18 & STH 12 \& I94 & 10 & 11 & 7 & 0.833 & 14 & 22 & 37 & $0.047^{* *}$ & 24 & 33 & 27 & 0.106 \\
\hline 19 & Main St (Reedsburg) & 12 & 11 & -6 & 0.871 & 37 & 29 & -28 & 0.262 & 49 & 40 & -22 & 0.290 \\
\hline 20 & W Pike St \& Linn St & 25 & 19 & -32 & 0.302 & 36 & 26 & -38 & 0.162 & 61 & 45 & -35 & $0.091^{* *}$ \\
\hline 21 & STH23 \& I94 & 13 & 13 & 0 & 0.990 & 36 & 35 & -3 & 0.869 & 49 & 48 & -2 & 0.889 \\
\hline 22 & 8th/Water St. \& STH 33/113 & 8 & 13 & 37 & 0.125 & 44 & 42 & -4 & 0.835 & 52 & 55 & 6 & 0.704 \\
\hline 23 & Phillips Blvd. (US 12) & 10 & 14 & 28 & 0.255 & 72 & 45 & -60 & $0.010^{* *}$ & 82 & 59 & -39 & $0.035^{* *}$ \\
\hline 24 & STH 47 \& USH 10 Interchange & 6 & 16 & 63 & $<0.001^{* *}$ & 33 & 44 & 25 & $0.092^{*}$ & 39 & 60 & 35 & $0.002^{* *}$ \\
\hline 25 & $\begin{array}{l}\text { Winneconne Ave from } \\
\text { I41 to Wisconsin Ave }\end{array}$ & 37 & 27 & -38 & 0.160 & 101 & 68 & -48 & $0.007^{* *}$ & 138 & 96 & -44 & $0.003^{* *}$ \\
\hline 26 & Main St (Downtown) & 32 & 33 & 4 & 0.851 & 66 & 62 & -6 & 0.678 & 98 & 96 & -2 & 0.879 \\
\hline 27 & I41 from 9th Ave to STH 44 Interchange & 40 & 38 & -5 & 0.810 & 117 & 111 & -6 & 0.613 & 157 & 150 & -4 & 0.641 \\
\hline & All Sites & 290 & 325 & 10.8 & $0.070^{*}$ & 754 & 708 & -6.5 & 0.149 & 1044 & 1032 & -1.1 & 0.761 \\
\hline
\end{tabular}

${ }^{*}$ Results significant at $90 \%$ level of confidence; ${ }^{*}$ Results significant at $95 \%$ level of confidence. 
crashes. 15 sites experienced a decrease in FI crashes during the pilot period, 11 an increase in FI crashes, and one site saw no change. However, none of the sites experiencing an increase in crashes were significant, while four sites experienced a significant decrease in FI crashes (at the $95 \%$ level of confidence). Aggregating all sites, FI crashes decreased significantly (at 90\% confidence level) by $10.8 \% .11$ sites experienced a decrease in PDO crashes, while 16 had an increase. Four of the sites experienced a significant increase in PDO crashes, while five saw a significant decrease in PDO crashes. No significant change in PDO crashes was noted when aggregating all data. Individually, 14 sites saw a decrease in total crashes during the pilot period (three significant), while 13 sites had an increase (five significant). Overall, total crashes were not affected significantly by targeted enforcement at hot spot locations. While these results are promising, officers expressed skepticism that the hot spot detection tool and targeted enforcement would not change driver behavior.

\section{Conclusions}

The Community Maps predictive crash hot spot detection tool provides a free to use, data-driven approach to help law enforcement agencies schedule resources based on traffic safety considerations. The tool was developed to create highlevel decision support capabilities that can analyze locations, date and time, and driver behaviors. The tool is scalable from municipality to statewide levels, making complex, expensive analyses available to all agencies. Visualizations and reporting capabilities provide detailed information about traffic safety, useful for enforcement and educational outreach. The hot spot detection tool enables quick queries and reproducible results, allowing for "what if" analyses, placing enhanced analysis capabilities in the hands of law enforcement decision makers at any agency.

When considering hot spot detection useful in a law enforcement context, the development of predictive traffic safety tools and corresponding targeted enforcement pilot brings to light several considerations. First and foremost, for the tool is useful to law enforcement agencies, the law enforcement officers must have confidence in the results and in the effectiveness of targeted enforcement. One important consideration is the inclusion of local roads, which provides a complete picture of crash patterns within a jurisdiction, allowing small municipalities to harness the capabilities of the tool. Disjoint, well-defined sets of hot spots were preferable to continuous heatmaps, as law enforcement agencies preferred specific locations to send officers to patrol. Further, the tool must support realtime, dynamic queries based on fast algorithms, allowing agencies to interactively run multiple queries (such as locations with high alcohol crashes, or locations of high weekend crashes involving teen drivers) on timely data. Finally, the inclusion of citation and warning data and calls for service would provide another dataset for use to determine with more accuracy where driver behavior issues, such as alcohol or distracted driving are prevalent. 
As a proof of concept, the hot spot detection tool was used to identify hot spots across Wisconsin. In 2019, a targeted enforcement pilot was deployed covering multiple jurisdictions and regions in the State of Wisconsin. Analysis of citations and warnings found that sites targeted for speeding and seatbelt violations officers were almost twice as likely to issue citations or warnings than at sites not targeted for those behaviors. Additionally, a crash analysis during the pilot months found that fatal and injury crashes were significantly reduced with targeted enforcement by law enforcement officers. Despite officer skepticism of the program, the results show that the hot spot detection tool output locations with a high volume of offenders that could be deterred with targeted enforcement. Additionally, the impact of targeted enforcement at these hot spots can have a positive impact on traffic safety.

The hot spot detection tool developed herein works well locating hot spots, with some measure of statistical significance. However, further research will help advance the algorithm "toward ideal hotspot detection". The first consideration is the use of the z-score for statistical significance, which provides an effective standardized measure for the returned hotspots but may not be ideal if the distribution of crashes is not normally distributed or the sample size is small. Moreover, ideal thresholds in terms of crashes and coverage area for given Analysis Areas to warrant confidence in the likelihood of deterring aberrant driver behavior through targeted enforcement activities need to be explored. Finally, longer term impacts of targeted traffic enforcement on hot spots need to be understood, as well as how best to develop and deploy predictive policing tools that are useful law enforcement agencies to further the traffic safety mission. The algorithm proposed in this paper provides an essential foundation for these future extensions.

\section{Acknowledgements}

Community Maps and the crash hot spot detection tool were developed by the Traffic Operations and Safety (TOPS) Laboratory in partnership with WisDOT Bureau of Transportation Safety (BOTS) through the Wisconsin Traffic Records Coordinating Committee (TRCC). 2019 pilot data was provided by BOTS. The opinions expressed herein are those of the authors, and do not reflect the opinions or views of WisDOT or the TRCC.

\section{Conflicts of Interest}

The authors declare no conflicts of interest regarding the publication of this paper.

\section{References}

[1] Reaves, B. (2010) Local Police Departments, 2007. US Department of Justice, Bureau of Justice Statistics.

[2] National Highway Traffic Safety Administration (NHTSA) and International Association of Chiefs of Police (IACP) (2003) Traffic Safety Strategies for Law Enforce- 
ment.

https://www.theiacp.org/sites/default/files/all/t/TrafficSafetyStrategiesCompleteRep ort.pdf

[3] Wisconsin Traffic Operations and Safety Laboratory (2020) Community Maps: Wisconsin County TSC Crash Mapping, May. https://communitymaps.wi.gov

[4] National Academies of Sciences, Engineering, and Medicine (2018) Proactive Policing: Effects on Crime and Communities. The National Academies Press, Washington DC.

[5] Sherman, L.W., Buerger, M. and Gartin, P. (1989) Repeat Call Address Policing: The Minneapolis RECAP Experiment. Crime Control Institute, Washington DC.

[6] Sherman, L.W. and Weisburd, D. (1995) General Deterrent Effects of Police Patrol in Crime "Hot-Spots": A Randomized Controlled Trial. Justice Quarterly, 12, 626648. https://doi.org/10.1080/07418829500096221

[7] Weisburd, D. and Green, L. (1995) Policing Drug Hotspots: The Jersey City Drug Market Analysis Experiment. Justice Quarterly, 12, 711-735.

https://doi.org/10.1080/07418829500096261

[8] Mastrofski, S.D. and Fridell, L. (n.d.) Police Departments' Adoption of Innovative Practice. National Police Research Platform. http://static1.1.sqspcdn.com/static/f/733761/26580910/1443907094233/Department + Characteristics+Survey.pdf?token=1xxue9jmC71p\%2BeA7gpKCf2WEf7U\%3D

[9] Braga, A.A., Papachristos, A.V. and Hureau, D.M. (2014) The Effects of Hot Spots Policing on Crime: An Updated Systematic Review and Meta-Analysis. Justice Quarterly, 31, 633-663. https://doi.org/10.1080/07418825.2012.673632

[10] Sherman, L.W. and Eck, J. (2002) Policing for Prevention. In: Sherman, L.W., Farrington, D., Welsh, B.C. and MacKenzie, D.L., Eds., Evidence Based Crime Prevention, Routledge, New York, 295-329. https://doi.org/10.4324/9780203166697 chapter 8

[11] Weisburd, D.L. and Eck, J. (2004) What Can Police Do to Reduce Crime, Disorder, and Fear? The ANNALS of the American Academy of Political and Social Science, 593, 42-65. https://doi.org/10.1177/0002716203262548

[12] Weisburd, D.L., Braga, A.A., Groff, E.R. and Wooditch, A. (2017) Can Hot Spot Policing Reduce Crime in Urban Areas? An Agent-Based Simulation. Criminology, 55, 137-173. https://doi.org/10.1111/1745-9125.12131

[13] Mohler, G.O., Short, M.B., Malinowski, S., Johnson, M., Tita, G.E., Bertozzi, A. and Brantingham, J. (2015) Randomized Controlled Field Trials of Predictive Policing. Journal of the American Statistical Association, 110, 1399-1411. https://doi.org/10.1080/01621459.2015.1077710

[14] Hunt, P., Saunders, J. and Hollywood, J.S. (2014) Evaluation of the Shreveport Predictive Policing Experiment. RAND, Santa Monica.

[15] Koper, C.S. (2014) Assessing the Practice of Hot Spots Policing: Survey Results from a National Convenience Sample of Local Police Agencies. Journal of Contemporary Criminal Justice, 30, 123-146. https://doi.org/10.1177/1043986214525079

[16] Turnbull, L.S., Hendrix, E.H. and Dent, B.D. (2000) Atlas of Crime: Mapping the Criminal Landscape. Oryx Press, Phonex.

[17] Bruce, C.W. (2009) Chapter 1: Fundamentals of Crime Analysis. In: Gwinn, S., Bruce, C.W., Cooper, J. and Hick, S.R., Eds., Exploring Crime Analysis. Readings on Essential Skills, 2nd Edition, BookSurge, LLC, North Charleston.

[18] Eck, J.E., Chainey, S., Cameron, J.G., Leitner, M. and Wilson, R.E. (2005) Mapping 
Crime: Understanding Hot Spots. U.S. Department of Justice; Office of Justice Programs; National Institute of Justice.

[19] (2010) Highway Safety Manual (1st Edition, Vol. 1). American Association of State Highway and Transportation Officials, Washington DC.

[20] Hauer, E. (1996) Identification of Sites with Promise. Transportation Research Record: Journal of the Transportation Research Board, 1542, 54-60. https://doi.org/10.1177/0361198196154200109

[21] Lord, D. and Mannering, F. (2010) The Statistical Analysis of Crash-Frequency Data: A Review and Assessment of Methodological Alternatives. Transportation Research Part A: Policy and Practice, 44, 291-305. https://doi.org/10.1016/j.tra.2010.02.001

[22] Ester, M., Kriegel, H.P., Sander, J. and Xu, X. (1996) A Density-Based Algorithm for Discovering Clusters in Large Spatial Databases with Noise. Proceedings of the 2 nd International Conference on Knowledge Discovery and Data Mining, 96, 226-231.

[23] Campello, R.J., Moulavi, D. and Sander, J. (2013) Density-Based Clustering Based on Hierarchical Density Estimates. In: Pei, J., Tseng, V.S., Cao, L., Motoda, H. and Xu, G., Eds., Pacific-Asia Conference on Knowledge Discovery and Data Mining, Springer, Berlin, Heidelberg, 160-172. https://doi.org/10.1007/978-3-642-37456-2 14

[24] Ankerst, M., Breunig, M.M., Kriegel, H.P. and Sander, J. (1999) OPTICS: Ordering Points to Identify the Clustering Structure. ACM Sigmod Record, 28, 49-60. https://doi.org/10.1145/304181.304187

[25] Khan, G., Santiago-Chaparro, K.R., Qin, X. and Noyce, D.A. (2009) Application and Integration of Lattice Data Analysis, Network K-Functions, and GIS to Study IceRelated Crashes. Transportation Research Record: Journal of the Transportation Research Board, 2136, 67-76. https://doi.org/10.3141/2136-08

[26] Lu, X.X., Chitturi, M., Ooms, A.W. and Noyce, D.A. (2010) Ordinal Discrete-Choice Analyses of Wisconsin Cross-Median Crash Severities. Transportation Research Record: Journal of the Transportation Research Board, 2148, 47-58. https://doi.org/10.3141/2148-06

[27] Chitturi, M., Ooms, A.W., Bill, A.R. and Noyce, D.A. (2011) Injury Outcomes and Costs for Cross-Median and Median Barrier Crashes. Journal of Safety Research, 42, 87-92. https://doi.org/10.1016/j.jsr.2011.01.006

[28] Khan, G., Bill, A.R. and Noyce, D.A. (2015) Exploring the Feasibility of Classification Trees versus Ordinal Discrete Choice Models for Analyzing Crash Severity. Transportation Research Part C: Emerging Technologies, 50, 86-96. https://doi.org/10.1016/j.trc.2014.10.003

[29] Ziakopoulos, A. and Yannis, G. (2020) A Review of Spatial Approaches in Road Safety. Accident Analysis \& Prevention, 135, 105323. https://doi.org/10.1016/j.aap.2019.105323

[30] Getis, A. and Ord, J.K. (1992) The Analysis of Spatial Association by Use of Distance Statistics. In Perspectives on Spatial Data Analysis. Geographic Analysis, 24, 189-206. https://doi.org/10.1111/j.1538-4632.1992.tb00261.x

[31] Ord, J.K. and Getis, A. (1995) Local Spatial Autocorrelation Statistics: Distributional Issues and an Application. Geographical Analysis, 27, 286-306. https://doi.org/10.1111/j.1538-4632.1995.tb00912.x

[32] Khan, G., Qin, X. and Noyce, D.A. (2008) Spatial Analysis of Weather Crash Patterns. Journal of Transportation Engineering, 134, 191-202. https://doi.org/10.1061/(ASCE)0733-947X(2008)134:5(191) 
[33] Truong, L.T. and Somenahalli, S.V. (2011) Using GIS to Identify Pedestrian-Vehicle Crash Hotspots and Unsafe Bus Stops. Journal of Public Transportation, 14, 6. https://doi.org/10.5038/2375-0901.14.1.6

[34] Rankavat, S. and Tiwari, G. (2013) Pedestrian Accident Analysis in Delhi Using GIS. Journal of the Eastern Asia Society for Transportation Studies, 10, 1446-1457.

[35] Xie, Z. and Yan, J. (2008) Kernel Density Estimation of Traffic Accidents in a Network Space. Computers, Environment and Urban Systems, 32, 396-406. https://doi.org/10.1016/j.compenvurbsys.2008.05.001

[36] NHTSA (2014) Data-Driven Approach to Crime and Traffic Safety (DDACTS): Operational Guidelines. Publication DOT HS 811 185. NHTSA, U.S. Department of Transportation.

[37] Williams, J. (2020) Effect of High-Visibility Enforcement on Motor Vehicle Crashes. https://nij.ojp.gov/topics/articles/effect-high-visibility-enforcement-motor-vehicle-c $\underline{\text { rashes }}$

[38] Wolfe, P.D. (2018) A Comprehensive Law Enforcement Deployment Model to Reduce Fatal and Serious-Injury Motor Vehicle Crashes Caused by Drunk Drivers in Wisconsin. Master's Thesis, University of Wisconsin-Platteville, Platteville.

[39] National Highway Traffic Safety Administration (1997) The Peoria Experience, Traffic Enforcement and Crime: It Plays in Peoria. Washington DC.

[40] McGarrell, E.F., Chernak, S. and Weiss, A. (2002) Reducing Gun Violence: Evaluation of the Indianapolis Police Department's Directed Patrol Project (Report 188740). National Institute of Justice, Washington DC.

[41] Stuster, J. (2001) Albuquerque Police Department: Safe Streets Program (Report DOT HS 809 278). National Highway Transportation Safety Administration, Washington DC.

[42] Weiss, A. and Morckel, K. (2007) Strategic and Tactical Approaches to Traffic Safety. Police Chief Magazine, 74, 20-23.

[43] Kuo, P.-F., Lord, D. and Walden, T.D. (2013) Using Geographical Information Systems to Effectively Organize Police Patrol Routes by Grouping Hot Spots of Crash and Crime Data. Journal of Transport Geography, 30, 138-148. https://doi.org/10.1016/j.jtrangeo.2013.04.006

[44] Burrell, A.L. (2018) Wisconsin State Patrol 2018 Annual Report. Wisconsin State Patrol, Wisconsin Department of Transportation.

[45] Qin, X., Parker, S.T., Liu, Y., Graettinger, A.J. and Forde, S. (2013) Intelligent Geocoding System to Locate Traffic Crashes. Accident Analysis and Prevention, 50, 1034-1041. https://doi.org/10.1016/j.aap.2012.08.007

[46] Nie, Q., Crawford, P.S., Bill, A., Parker, S.T., Graettinger, A.J., Smith, R.K., Elliot, T.B. and Paschal, E.N. (2021) Electronic Crash Reporting: Implementation of the Model Minimum Uniform crash Criteria (MMUCC) and Crash Record Life Cycle Comparison. Transportation Research Interdisciplinary Perspectives, 9, 100318. https://doi.org/10.1016/j.trip.2021.100318

[47] Hauer, E. (1997) Observational Before-After Studies in Road Safety: Estimating the Effects of Highway and Traffic Engineering Measures on Road Safety. Emerald Group Publishing Limited, Bingley. 